http://dx.doi.org/10.11606/issn.2238-6149.v27i1pi-ii

\title{
Pesquisa em Terapia Ocupacional: desafios para avançar
}

\author{
Elisabete Ferreira Mângia*, Selma Lancman*
}

Apresentamos aos nossos leitores mais um fascículo da Revista de Terapia Ocupacional da USP, composto por trabalhos de docentes pesquisadores, pós-graduandos e alunos de graduação de conceituadas instituições de pesquisa e ensino: Universidade Federal de Minas Gerais (UFMG); Universidade Federal da Paraíba (UFPB); Universidade Federal de São Carlos (UFSCAR); Universidade Federal de Campinas (UNICAMP); Universidade Federal do Paraná (UFPR); Universidade Federal do Triangulo Mineiro (UFTM); Universidade de São Paulo (USP), campus São Paulo e Ribeirão Preto, Universidade Estadual Paulista - Marília (UNESP) e Faculdade de Ciências Médicas de Minas Gerais (FCMMG)

Os artigos contemplam diversificadas áreas de atenção nos campos da saúde e reabilitação psicossocial: serviços de saúde mental, infância e adolescência, processos de aprendizagem, atenção ao idoso, atenção às pessoas com deficiências sensoriais e físicas, consultoria colaborativa e apoio social.

Os trabalhos denotam que pesquisadores da área, em que pese o conjunto de obstáculos que encontram no país, têm conseguido avançar na diversificação de objetos de estudo, áreas de intervenção e técnicas de investigação.

Salientamos a publicação de dois artigos que apresentam respectivamente as versões brasileiras de dois importantes instrumentos: "Avaliação de confiabilidade e a validade de construto da versão brasileira do Social Support Appraisals" que visa avaliar a percepção de crianças e adolescentes sobre o apoio social recebido da família, amigos, professores e outras pessoas da comunidade.

E, “Adaptação transcultural e reprodutibilidade do Measure of the Quality of the Environment" em indivíduos com hemiparesia, instrumento que busca mensurar o impacto de fatores ambientais na funcionalidade.

O emprego de instrumentos de avaliação validados se constitui em recurso importante de apoio á clínica e a pesquisa e têm sido negligenciados na maior parte dos cenários de ensino de graduação e na própria pesquisa. Vemos hoje, cada vez mais, a necessidade de que pesquisadores da área reconheçam os limites atuais de formalização de projetos e resultados de pesquisa e empreendam processos formativos que possam geram uma produção mais madura e consistente.

$\mathrm{Na}$ atualidade, o cenário da pesquisa se mostra adverso à áreas emergentes e o furor produtivista muitas vezes constrange os pesquisadores a adotarem estratégias muito simplificadas de investigação capazes de gerar produtos à curto prazo.

Em todo o mundo, pensadores críticos a esse modelo, apontam que tal cenário tem levado ao empobrecimento da produção científica, em especial na área da saúde, o que em nada contribui para as coletividades.

É importante que docentes sigam contribuindo com a pesquisa nas áreas de atuação profissional da Terapia Ocupacional e em avaliações em profundidade sobre os resultados das intervenções desenvolvidas nas Redes de Atenção à Saúde e Intersetoriais. Para tanto vale a pena adotar desenhos mais complexos de pesquisa e, em especial, ousar desenvolver estudos de segmento, raros em nosso país.

* Editoras da Revista de Terapia Ocupacional da USP, Docentes do Curso de Terapia Ocupacional da Faculdade de Medicina da Universidade de São Paulo. 
A adoção de linguagens comuns que orientem as ações técnicas no campo da Reabilitação Psicossocial é outro ponto que deve ser considerado. A Classificação Internacional de Funcionalidade, Incapacidade e Saúde (CIF) se apresenta como um recurso importante, mas novamente vemos que foram poucos os cursos de Terapia Ocupacional que aceitaram o desafio proposto pela Organização Mundial da Saúde (OMS) para sua ampla adoção.

Pensar na importância de situar às práticas de Terapia Ocupacional em contexto interprofissional é uma das maneiras de obter avanços consistentes na pesquisa. Deixar de lado os modelos redutivos que veem apenas a prática uniprofissinal ou não levam em conta os contextos nos quais as ações e tratamentos são desenvolvidos, são caminhos que podem ser adotados.

Finalmente, buscar avanços na formalização do texto acadêmico e particularmente nos artigos científicos é de enorme importância para se obter melhores oportunidades de publicação em periódicos nacionais em internacionais.

Mais do que as demais áreas a Terapia Ocupacional se encontra ainda em posição de grande fragilidade, parte dessa situação poderia ser melhor equacionada se houvesse ampla conscientização de docentes e pesquisadores sobre esses assuntos.

Esperamos que as contribuições de nossos autores contribuam para impulsionar a pesquisa e a reflexão na área e que possamos mais e mais qualificar e ampliar nossa produção. 